\title{
Multidrug resistance and rhabdomyosarcoma (Review)
}

\author{
CONSOLACIÓN MELGUIZO ${ }^{1}$, JOSE PRADOS ${ }^{1}$, ANA R. RAMA ${ }^{2}$, RAÚL ORTIZ ${ }^{2}$, \\ PABLO J. ÁLVAREZ ${ }^{1}$, JUAN E. FERNÁNDEZ ${ }^{1}$ and ANTONIA ARANEGA ${ }^{1}$ \\ ${ }^{1}$ Institute of Biopathology and Regenerative Medicine (IBIMER), Departamento de Anatomía y Embriología, Facultad de \\ Medicina, Universidad de Granada, E-18071 Granada; ${ }^{2}$ Department of Health Science, University of Jaén, Jaén, Spain
}

Received February 23, 2011; Accepted April 18, 2011

DOI: $10.3892 /$ or.2011.1347

\begin{abstract}
Classical cytotoxic treatment of rhabdomyosarcoma (RMS) is often accompanied by significant morbidity and poor response. This cytotoxic therapy may induce a multidrug resistance (MDR) phenotype in RMS which is associated with decreased effectiveness of chemotherapy. The majority of MDR molecules belong to a family of ABC (ATP binding cassette) transporters. Studies of drug resistance in RMS suggest that there are various mechanisms acting simultaneously, which might explain the low percentage of long-term survival in this malignancy. Moreover, although cells exposed to cytotoxic agents increase expression of muscle differentiation markers indicating myogenic differentiation, multidrug resistance may be a major obstacle in differentiation therapy for RMS. This review briefly discusses the current knowledge of resistance in RMS and emphasizes the importance of understanding the different aspects of MDR status in these patients.
\end{abstract}

\section{Contents}

1. Introduction

2. Molecular mechanism of drug resistance in tumours

3. Rhabdomyosarcoma and multidrug resistance

4. Multidrug resistance and rhabdomyosarcoma differentiation

5. Conclusions

\section{Introduction}

Rhabdomyosarcomas (RMS) are a distinct type of soft tissue sarcoma (STS), arising from primitive mesenchymal cells with varying degrees of skeletal muscle differentiation. They

Correspondence to: Dr Jose Prados, Instituto de Biopatología y Medicina Regenerativa (IBIMER), Departamento de Anatomía y Embriología, Facultad de Medicina, Universidad de Granada, E-18071 Granada, Spain

E-mail: jcprados@ugr.es

Key words: rhabdomyosarcoma, multidrug resistance, differentiation are the most common childhood STS, accounting for $4-8 \%$ of all pediatric malignancies. About two-thirds of all sarcomas and $7-8 \%$ of all solid malignant tumors in childhood are RMS (1). The two main histopathological subtypes of this malignancy in children are embryonal and alvelolar RMS (Fig. 1). Patient's prognosis depends on the localization of the primary lesion, histological subtype, stage of disease and the age at diagnosis (2-5). Until adolescence, RMS are still among the most common STS, but they become more infrequent with older age and are rarely seen in patients who are older than age 45 years (6).

Pediatric RMS has a more advantageous prognosis after multimodality treatment compared with adult RMS, which might be related to a decreased sensitivity to chemotherapy in adults (7). The development of resistance to chemotherapy is a major cause of failure in treating patients with malignant tumors, especially in advanced and relapsed cases. Most pediatric malignancies are initially chemosensitive; however, they can acquire MDR during chemotherapy $(8,9)$. Drugs commonly used for the treatment include vinca-alkaloids, actinomycin D, alkylating agents and anthracyclines (10). RMS is not curable through chemotherapy alone (11).

\section{Molecular mechanism of drug resistance in tumours}

Numerous factors affect the bioavailability and efficacy of chemotherapeutic drugs, including the method of drug administration, absorption, metabolism, blood supply and tissue oxygenation, and fundamental defects in the responses of tumour cells to injury. What is clear, however, is that chemotherapy has made a significant contribution to the treatment of many haematological and pediatric neoplasms but has been much less beneficial for the treatment of adult solid tumours. Even where some benefit has occurred, initial response to therapy is often superseded by the acquisition of drug resistance, or the over-growth of drug-resistant clones. The ability of a small population of malignant cells to survive exposure to lethal doses of cytotoxic agents and to develop resistance to those agents has determined the very nature of the practice of oncology. Modern chemotherapy has partially overcome the twin problems of relapse and the emergence of drug resistance by optimizing cytotoxicity. The combination of drugs used in treatment programs, the duration of protocols, and the dose and frequency of administration of antineoplastic agents have been determined, in part, by strategies designed to reduce the 


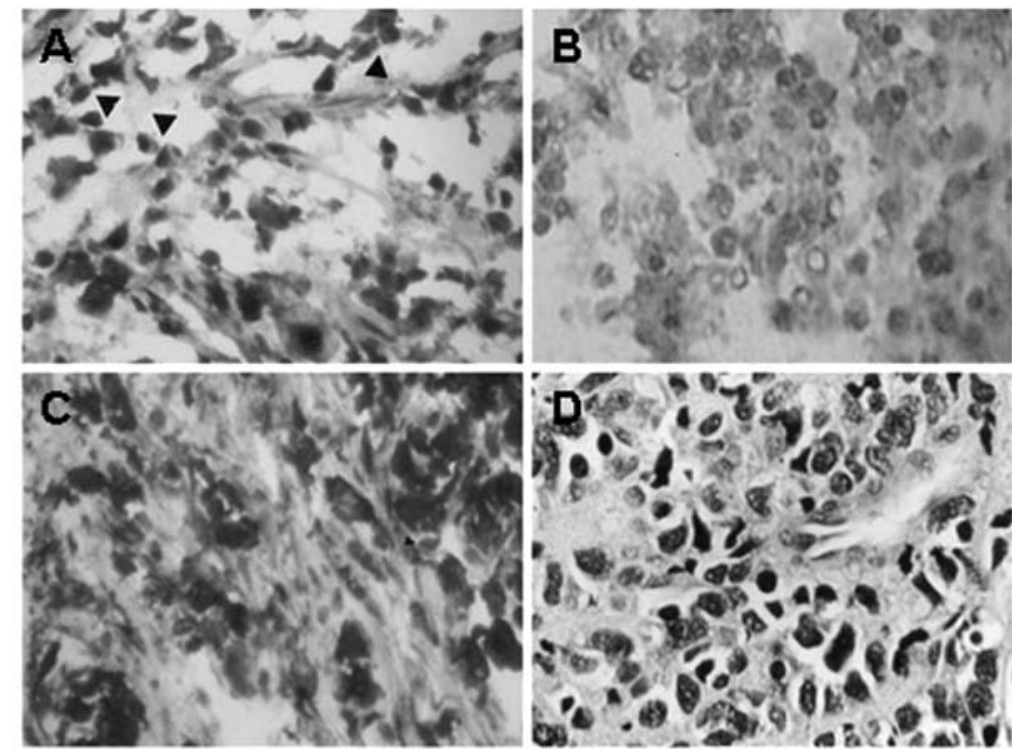

Figure 1. Representative images of histopathological subtypes of RMS. Rhabdomyosarcoma, the most common soft tissue sarcomas observed in children, are roughly divided into two major subtypes: embryonal and alveolar. (A) Alveolar RMS showing an intense (arrows) desmin expression. (B) Alveolar RMS staining with myoglobin. (C) Embryonal RMS staining with desmin. (D) Hematoxylin-eosin staining of an embryonal RMS.
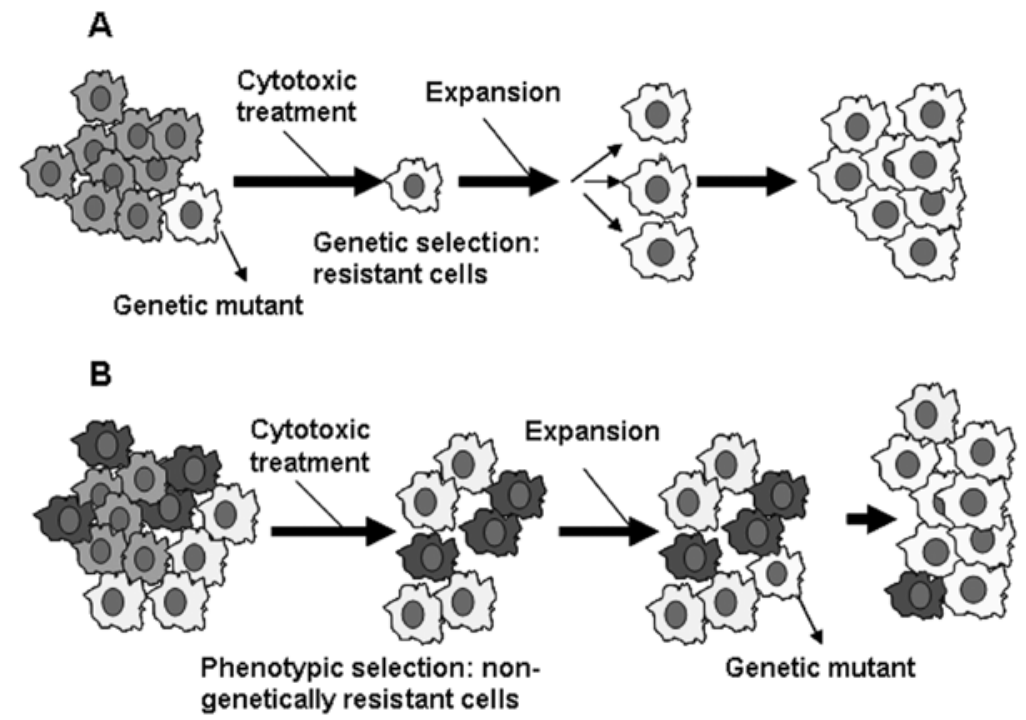

Figure 2. Development of cancer drug resistance. (A) Homogeneous population of cancer cells with genetic mutant (resistant cells) which are selected by cytotoxic treatment. (B) Heterogeneous population of cancer cells. Phenotypically resistant cell subpopulation is selected by cytotoxic treatment. The expansion of these variants increases the chance of generating genetically mutant (resistant cells).

possibility of emergence of a resistant population of cells (Fig. 2).

A number of possible molecular explications for drug resistance exist. There may be exclusion of drug from the cell, failure to activate the prodrug to its active form, increased detoxification, alterations in the drug target, enhanced repair capability of the cell after injury, or failure to engage an appropiate response, leading to apoptosis in the damaged cell. Many of these factors may co-exist in human tumours; some are a feature of cell lineage whilst others appear de novo during disease progression (12).

Multidrug resistance mediated by P-glycoprotein. Characteristically, it became obvious that tumour cells which were resistant to one drug often showed cross-resistance to a wide variety of other, structurally unrelated drugs (Table I). This phenomenon of MDR was associated of a $170-\mathrm{kDa}$ protein, P-glycoprotein (P-gp), the product of the $m d r l$ gene, which was first detected in samples from patients with clinical multidrug resistant ovarian cancer (13). P-Glycoprotein is an energy dependent transport protein which has a physiological function in cellular detoxification and secretion mechanisms. Ling and Thompson (14) using Chinese hamster ovary cells, were the first to show that MDR was associated with decreased intracellular drug accumulation and the first to identify the presence of P-gp in these MDR cells. It has been demonstrated that the expression of this protein is frequently increased in pediatric solid malignancies (15). P-glycoprotein is a member 
Table I. P-gp substrates and modulators.

\begin{tabular}{|c|c|}
\hline Group & Drug \\
\hline \multicolumn{2}{|l|}{ Substrates } \\
\hline \multicolumn{2}{|l|}{ Antitumor agents } \\
\hline Taxanes & Docetaxel, paclitaxel \\
\hline Epipodophyllotoxins & Etoposide, teniposide \\
\hline Anthracyclines & Doxorubicin, daunorubicin \\
\hline Vinca alkaloids & Vinblastine, vincristine \\
\hline Cytotoxic agents & Colchicines, actinomycin D, mitoxantrone \\
\hline Steroids & Hydrocortisone, corticosterone, dexametasone, methylprednisolone, aldosterone \\
\hline Antibiotics & Erytromycin, tetracycline, rifampin \\
\hline Antiemetic and antiacids & Ondansetron, cimetidine, ranitidine \\
\hline$\beta$-adrenoceptor antagonists & Reserpine, celiprolol, talinolol, bunitrolol, carvedilol \\
\hline Opioids & Morphine, pentazocine, methadone, asimadoline, fentanyl/loperamide, domperidone \\
\hline Cardiac glycosides & Digotoxin, digoxin \\
\hline \multicolumn{2}{|l|}{ Others } \\
\hline Antihelminthics & Ivermectin \\
\hline Detergents & Triton X-100, nonylphenol ethoxylate \\
\hline HIV protease inhibitors & Amprenavir, ritonavir, indinavir, saquinavir, nelfinavir \\
\hline Ionophores & Gramicidin D, nonactin, beauvericin \\
\hline \multicolumn{2}{|l|}{ Modulators } \\
\hline Cyclic peptides & Cyclosporin A, PSC833 \\
\hline $\mathrm{Ca}^{2+}$ channel blockers & Verapamil, nifedipine, azidopine, dexniguldipine \\
\hline Steroids & Progesterona, tamoxifen, cortisol \\
\hline Calmodulin antagonists & Trifluoperazine, chloropromazine, trans-flupethixol \\
\hline Others & Reserpine, amiodarone, terfenadine, disulfiram, quinidine, chloroquine \\
\hline
\end{tabular}

of a multigene family with alternative splicing patterns and the differential expression of various P-glycoprotein genes may result in varying levels of resistance to drugs (16). P-glycoprotein expression is apparently regulated on many different levels. These include amplification, transcriptional and translational regulation of expression and mechanism affecting P-glycoprotein stability or activity (17).

$M R P$ and drug resistance. It has become increasingly clear how important a role the multidrug resistance-associated protein (MRP) plays in the ineffectiveness of treatment with cytotoxic drugs in some types of cancer (18). The discovery of MRP was performed in the line H69AR, adriamycin selected from the H69 small cell lung cancer line (19). Subsequently, the transfection of mrp gene in HeLa cells showed that this protein confer resistance to chemotherapeutic agents (20). With a $6.5-\mathrm{Kb}$ mRNA, MRP is a protein of 1531 amino acids and has a molecular weight of $190 \mathrm{kDa}$. Although different in the primary structure of P-gp (only $15 \%$ of its amino acid overlap), both confer resistance to a similar set of chemotherapeutic agents. As in the case of P-gp, MRP belong to the superfamily of $\mathrm{ABC}$ transporters and contains a hydrophobic transmembrane region and a domain that binds to cytoplasmic nucleotides, preferably at ATP where lies the greatest homology with the sequence P-gp (21) (Fig. 3). The mrp gene has been mapped to chromosome 16 and is expressed at low levels in many tissues, including testis, skeletal muscle, heart, kidney, lung and hematopoietic cells. It is also detectable in brain, spleen, liver and intestine. However, the physiological functions of MRP in these tissues are not clearly understood (22). In tumors, MRP confers drug resistance by a mechanism similar to P-gp. Today we know that MRP exists in a variety of tumor types, including sarcomas, leukemia, cancer, small cell lung, breast, cervical, prostate and bladder carcinomas. Preliminary studies indicate that MRP mRNA levels are elevated in neuroblastomas and RMS (23).

LRP and drug resistance. LRP (resistance-related protein in lung) is a $110-\mathrm{kDa}$ protein not related to $\mathrm{P}-\mathrm{gp}$ and described in the 2R120 lung cancer cell line, obtained from SW1573 cells by exposure to doxorubicin (24). The lrp gene has been localized to the short arm of chromosome 16, close to the mrp gene but $m r p$ and $l r p$ are rarely co-amplified. It is overexpressed in negative cells for P-gp. Like P-gp and MRP, LRP appears widely distributed in normal tissue type bronchial epithelium, digestive tract, keratinocytes, adrenal cortex, macrophages, kidney, pancreas and germ cells (25). The presence of LRP in different cell types, suggests that the 'vaults' have a common basic physiological function $(26,27)$. The clinical significance of LRP as a mechanism of resistance has been reported. Tumors with reduced expression of LRP are the Wilms tumor, RMS, Ewing sarcoma and acute myeloid leukemia. Most other solid tumors are predominantly positive. The distribution of LRP in clinical specimens was consistent 


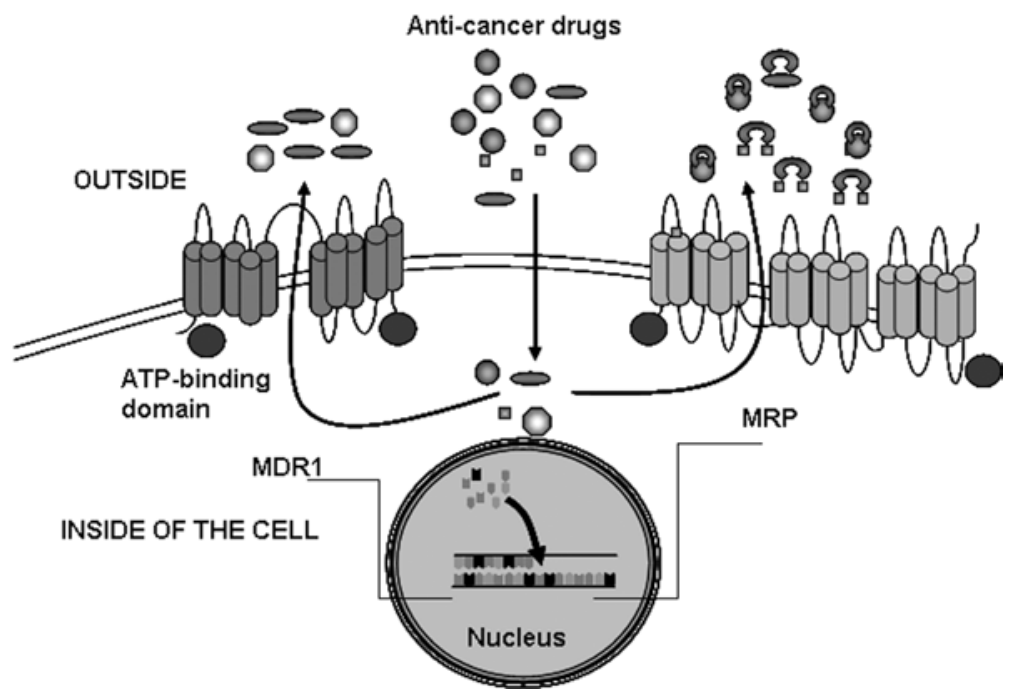

Figure 3. Multidrug resistance (MDR) is a significant impediment to the success of RMS chemotherapy. A typical form of MDR is attributable to the overexpression of membrane transport proteins such as P-glycoprotein and MRP, resulting in an increased drug efflux. The expression of this $\mathrm{ABC}$ protein decreases the response of cancer cells to multiple structurally unrelated chemotherapies.

with the in vitro data indicating a broad distribution of mechanisms associated with LRP, reflecting the different types of tumor response to chemotherapy (28).

Topoisomerases and drug resistance. The ability of normal cells to recover from the effects of cytotoxic drugs is obviously critical to any regime of therapy, and central to this is the cell's ability to repair damage. Topoisomerases may represent the final common pathway of cytotoxicity of several different classes of antineoplastic agents. Topoisomerases are enzymes that catalyze changes in the secundary and tertiary structures of DNA: theses enzymes are necessary for DNA replication. Most attention has focused on topoisomerase Il, an enzyme that is the target of antineoplastic drugs that act as DNAintercalating agents, such as etoposide. This new pattern of cross-resistance has been dubbed 'atypical MDR' and although the precise defect in these cells is not yet known, there is strong evidence implicating altered topoisomerase activity in the resistant cells (29).

Other enzymes as the mechanism of drug resistance. The role of anionic glutathione S-Transferase (GST) in clinical drug resistance has yet to be determined. Increased amounts of anionic GST mRNA have been found in colon cancer in comparison to normal surrounding colon mucosa by means of immunohistochemical techniques (30). Two different isoenzymes in the basic class of GST have been implicated in resistance to mechlorethamine and alkylating agents. The overexpression of glutathione S-transferases in tumors may reduce the reactivity of various anticancer drugs. In recent years it has become evident that glutathione S-transferases are also involved in the control of apoptosis through the inhibition of the JNK signaling pathway (31).

\section{Rhabdomyosarcoma and multidrug resistance}

RMS differs from other STS in their favorable response to chemotherapy. Greater than $60 \%$ of all patients survive a 5-year period after diagnosis due to multimodality treatment (32). Factors that determine a patient's prognosis include the site of the primary lesion, stage of disease, histologic subtype and age at diagnosis $(2,33,34)$. In addition, development of RMS drug resistance may an important prognostic factor. This phenomenon in several pediatric tumors such as RMS may be mediated by MDR-associated proteins P-gp, MRP and LRP $(7,23,35)$, among others.

The P-gp decreases the intracellular drug accumulation that correlates with the degree of drug resistance (7). Chan et al (35) found that P-gp expression assessed by immunohistochemistry was an adverse prognostic factor in pediatric RMS patients. However, these findings were not confirmed in a later study by Kuttesch et al (37). These two studies differed (at least partially) in the applied antigen retrieval method, the panel of antibodies, the method of immunostaining and the scoring of immunoreactivity. Komdeur et al (7) found a high percentage of P-gp-positive samples (43 of $45,96 \%)$ compared with the study of Chan et al (35) (9 of 30,30\%). This considerable difference might be caused by immunohistochemical procedures. A heatinduced epitope retrieval was performed in the first study, whereas this was not described in the second study. In addition, not all specimens in the first study were assessed with the C494 antibody, which was used to evaluate all cases in the second study. On the other hand, Klunder et al (38) compared the expression of MDR proteins in 13 pairs of primary untreated RMS and follow-up material obtained after chemotherapy. All, except two specimens obtained after chemotherapy, showed morphologic 'maturation' and increased desmin expression, as previously described (39-41). The two cases in which no further differentiation was observed correspond to local recurrences of the primary tumor which was resected after chemotherapy. The cause may be that primary chemosensitive clones re-emerged (42). On the other hand, studies in vitro (43) clearly showed that MDR mediated by $m d r l$ may be induced by treatment with actinomycin D. In addition, Melguizo et al (44) reported an increased P-gp- 
expression in another cell line of embryonal RMS by the same drug. In these two studies differentiation of RMS cells and resistance have an intense relationship which can be very important as we discuss later. Another mechanism of drug resistance is mediated by the MRP, which is also a membrane bound efflux pump, which decreases the concentration of cytotoxic agents within the cell. However, Seitz et al (8) showed that MRP genes do not have an effect on drug resistance in RMS. On the other hand, LRP, also known as the human major vault protein, is a structure involved in MDR against many structurally unrelated drugs. It is believed that LRP redistributes drugs within the cell, resulting in lower concen-trations at the target site (45). The range of drugs associated with LRP is even broader than those associated with P-gp and MRP1 and additionally includes alkylating agents (e.g., melphalan and cyclophosphamide) and platinum compounds (46-48). Klunder et al (38) reported a higher LRP protein expression in tumor specimen from adults compared to children. LRP and MDM2 might have an effect when the treatment is based in a single drug. In alveolar RMS, multidrug resistance was mediated via an MDR1- and MRP-dependent mechanism in vitro and in xenografts models with lower gene expression levels in xenotransplants (7). The three cases of alveolar RMS, which all occurred at a young adult age, had either non-existent or low LRP expression. When statistical analysis was performed after omitting the alveolar RMS, a significantly higher expression of LRP was found in adult tumors compared with pediatric tumors. In addition, excluding alveolar RMS resulted in an increased Spearman's @ when calculating the correlation between LRP expression and patient age. In conclusion, LRP expression is more pronounced in adult RMS compared with pediatric RMS and is correlated with age. As a genetically unrelated type, alveolar RMS displays no or limited expression of LRP. Finally, in RMS, overexpression of MDM2 was found in vitro (49) and in tumor samples (50). MDM2 protein binds and suppresses tumor suppressor gene p53 (51). Overexpression of MDM2 leads to overexpression of MDR1-gene and therefore results in an increase of P-gp (49).

In various pediatric malignant tumors, the expression of MDR-associated genes has been proven to increase in the primary untreated tumors (51-54). These results indicate that MDR-associated genes affect the 'primary drug resistance' in the first-line chemotherapy. However, the role of MDR associated genes in the 'acquired drug resistance' established during chemotherapy has rarely been investigated. P-gp and MRP1 are expressed frequently in RMS, but the expression does not differ between pediatric and adult samples (15). In RMS, Komdeur et al (7) assessed the expression of P-gp, MRP1, and LRP in 45 untreated tumor specimens. Most samples $(80 \%)$ are extensively P-gp positive. Most of the samples $(56 \%)$ are also extensively positive for MRP1. In contrast, a minority of samples (16\%) reveal extensive immunoreactivity for LRP. These results are consistent with Oue et al (15) study of MDR-associated gene expressions in RMS (75\%) shown MDR1/P-gp positive, and 0\% for LRP. MDR1, MRP1, and LRP, was newly observed or had increased in various pediatric malignant tumors by immunohistochemistry. The findings suggest that various MDR-associated genes contribute to primary drug resistance, with regard to the response to the first-line chemotherapy in the treatment of these tumors and the correlated expression of P-gp and MRP1 suggests that they operate under similar regulatory mechanisms. PituchNoworolska et al (23) reported in RMS, the expression of 3 or $4 \mathrm{MDR}$ proteins suggesting various mechanisms acting simultaneously, which might explain chemotherapy resistance and a low percentage of long-time survival in this malignancy.

Several explanations may account for the difference in outcome between pediatric and adult RMS patients. First, adults might present more often in a more advanced stage than children, this being an independent adverse prognostic factor (5). Although children presented more often with IRS Stage 1-3, and more adults presented with IRS Stage 4 disease, the differences were not statistically significant (7). Second, in young patients, the primary tumors often arise at sites that are linked with a more favorable response to treatment (32). Third, patients with embryonal RMS and especially those with the botryoid subtype have a more favorable prognosis than those with ARMS (56,57). Komdeur et al (7) found an equal distribution of P-gp expression between the pediatric and the adult groups suggests that P-gp is not a critical factor in the clinical behavior and no significant differences in MRP1 expression between specimens obtained from children and adults. The observed correlation between MRP1 and P-gp expression suggests that these drug efflux proteins are regulated by similar factors. Compared with P-gp and MRP1 expression, fewer LRP-positive RMS were encountered. LRP expression correlated with age. It is conceivable that LRP expression gradually increases over the total range of patient age. Increasing knowledge on the genetic and biologic make-up of alveolar RMS indicates that this type is basically distinct from other RMS (58). A recent report by Klunder et al (38) demonstrated that differentiation coincided with an increase in LRP expression (but not in the expression of P-gp or MRP1). They suggested that LRP expression enables RMS cells to survive chemotherapy.

\section{Multidrug resistance and rhabdomyosarcoma differentiation}

An essential aspect in the development of multidrug resistance in tumor cells is the relationship with the differentiation process. In fact, the 'differentiated' cells that remain after chemotherapy appear to represent a tumor subpopulation that is resistant to chemotherapy in an otherwise very chemosensitive tumour. This raises the question as to whether MDR may play a role in selective 'protection' of better-differentiated tumor cells (38). After chemotherapy, P-gp and MRP1 expression in differentiated cells remained essentially unchanged, whereas LRP expression increased significantly. These findings suggest P-gp and MRP1 possibly play a role in primary chemoresistance in RMS, whereas LRP may be involved in chemotherapy-induced MDR. The study by Marchal et al (59) of the embryonal RMS cell line RD revealed chemotherapy-induced differentiation not accompanied by up-regulation of MDR1 mRNA. This study further revealed that the differentiation induction or selective destruction may depend on the chemotherapeutic agent and/or dosage. These findings suggest heterogeneity in RMS with respect to both chemosensitivity and differentiation level. It is likely that the better-differentiated cells are more chemoresistant, which 
appears to be conveyed by expression of LRP. In contrast, another study by the same group showed up-regulation in two RMS cell lines, one of which was obtained after chemotherapy in vivo (60). In a study of various tumor types, Izquierdo et al (46) found that LRP expression was higher in differentiated tumor types and present in a number of refractory tumours after chemotherapy, including two RMS. In view of the current findings, (pre)terminal differentiation induced by chemotherapy might increase LRP-related MDR, which should be taken into consideration when planning further treatment.

The cellular differentiation induces a modulation of expression in some antigens including those which may be essential for the proliferation of tumor cells. This change may be related to the therapeutic response of the tumour, because it has been observed that patients with recurrences of well differentiated RMS have a poor prognosis $(61,62)$. Some authors have shown that low doses of actinomycin $\mathrm{D}$ are able to induce resistance in RMS cells in culture in which modulation of MHC expression took place $(63,64)$. Prados et al (63) indicated that positive RMS to $m d r l$ showed higher HLA class I expression than those which were negative to $m d r l$ PCR, which seems to prove a significant correlation between the expression of both molecules. These results demonstrated that conventional chemotherapy of embryonal RMS is able to induce resistance which can modulate HLA class I expression changing the possible immunoresponse against tumor cells.

\section{Conclusions}

The prognosis of RMS in advanced stages is still unsatisfactory. Therapy is limited due to local tumor recurrence, development of metastases and multidrug resistance. The activity of MDR proteins in tumour cells is associated with an increased resistance to therapy and in consequence with a decreased effectiveness of chemotherapy. The majority of MDR molecules belong to a family of $\mathrm{ABC}$ transporters. Effectiveness of conventional cytotoxic treatment of RMS may be limited by the development of MDR mediated by $m d r l, m r p$ and $l r p$ genes. The expression of LRP is induced by chemotherapeutic treatment in RMS in vivo. The preferential expression of LRP in differentiated cells and the subsequent more extensive expression after chemotherapy suggest that LRP plays a role in therapy-induced differentiation and is responsible for the resistant phenotype in most of these tumors. P-gp and MRP1 are expressed frequently in RMS, and their correlated expression suggests that they operate under similar regulatory mechanisms. High expression of an MDR protein profile in RMS suggests various mechanisms acting simultaneously, which may explain chemotherapy resistance and a low percentage of long-time survival in this tumour. New research in the up-regulation of these genes before and after chemo-therapy in pediatric malignancies such as neuroblastoma, hepatoblastoma, Wilms tumor and RMS will be necessary to understand the mechanism of drug resistance in pediatric malignancies.

\section{Acknowledgements}

The study was supported by the Autonomous Government of Andalucía (Project no. PI-0338).

\section{References}

1. Huh WW and Skapek SX: Childhood rhabdomyosarcoma: new insight on biology and treatment. Curr Oncol Rep 12: 402-410, 2010.

2. Crist WM, Anderson JR, Meza JL, et al: Intergroup rhabdomyosarcoma study-IV: results of patients with non-metastatic disease. J Clin Oncol 19: 3091-3102, 2001.

3. Newton WA Jr, Gehan EA, Webber BL, et al: Classification of rhabdomyosarcomas and related sarcomas. Pathologic aspects and proposal for a new classification- an Intergroup Rhabdomyosarcoma Study. Cancer 76: 1073-1085, 1995.

4. Lawrence W Jr, Anderson JR, Gehan EA and Maurer H: Pretreatment TNM staging of childhood rhabdomyosarcoma: a report of the Intergroup rhabdomyosarcoma Study Group. Children's cancer study group. Pediatric Oncology Group. Cancer 80: 1165-1170, 1997.

5. Crist WM, Garnsey L, Beltangady MS, et al: Prognosis in children with rhabdomyosarcoma: a report of the intergroup rhabdomyosarcoma studies I and II. Intergroup Rhabdomyosarcoma committee. J Clin Oncol 8: 443-452, 1990.

6. Ferrari A, Miceli R, Meazza C, et al: Soft tissue sarcomas of childhood and adolescence: the prognostic role of tumor size in relation to patient body size. J Clin Oncol 27: 371-376, 2009.

7. Komdeur R, Klunder J, van der Graaf WT, van den Berg E, de Bont ES, Hoekstra HJ and Molenaar WM: Multidrug resistance proteins in rhabdomyosarcomas: comparison between children and adults. Cancer 97: 1999-2005, 2003.

8. Seitz G, Warmann SW, Vokuhl CO, Heitmann H, Treuner C, Leuschner I and Fuchs J: Effects of standard chemotherapy on tumor growth and regulation of multidrug resistance genes and proteins in childhood rhabdomyosarcoma. Pediatr Surg Int 23: 431-439, 2007.

9. Keshelava N, Seeger RC, Groshen S and Reynolds CP: Drug resistance patterns of human neuroblastoma cell lines derived from patients at different phases of therapy. Cancer Res 58: 5396-5405, 1998.

10. Ferrari A and Casanova M: Current chemotherapeutic strategies for rhabdomyosarcoma. Expert Rev Anticancer Ther 5: 283-294, 2005.

11. Singer S, Demetri GD, Baldini EH and Fletcher CD: Management of soft-tissue sarcomas: an overview and update. Lancet Oncol 1: 75-85, 2000.

12. Fulda S: Targeting apoptosis resistance in rhabdomyosarcoma. Curr Cancer Drug Targets 8: 536-544, 2008.

13. Bell DR, Gerlach JH, Kartner N, Buick RN and Ling V: Detection of P-glycoprotein in ovarian cancer: a molecular marker associated with multidrug resistance. J Clin Oncol 3: 311-315, 1985.

14. Ling V and Thompson LH: Reduced permeability in CHO cells as a mechanism of resistance to colchicines. J Cell Physiol 83: 103-116, 1973.

15. Oue T, Yoneda A, Uehara S, Yamanaka H and Fukuzawa M: Increased expression of multidrug resistance-associated genes after chemotherapy in pediatric solid malignancies. J Pediatr Sur 44: 77-80, 2009.

16. Li Y, Yuan H, Yang K, Xu W, Tang W and Li X: The structure and functions of P-glycoprotein. Curr Med Chem 17: 786-800, 2010.

17. Sharom JJ: ABC multidrug transporters: structure, function and role in chemoresistance. Pharmacogenomics 9: 105-127, 2008.

18. Ishikawa T, Kuo MT, Furuta K and Suzuki M: The human multidrug resistance-associated protein (MRP) gene family: from biological function to drug molecular design. Clin Chem Lab Med 38: 893-897, 2000.

19. Mirski SE, Gerlach JH and Cole SP: Multidrug resistance in a human small cell lung cancer cell line selected in adriamycin. Cancer Res 47: 2594-2598, 1987.

20. Grant CE, Valdimarsson G, Hipfner DR, Almquist KC, Cole SP and Deeley RG: Overexpression of multidrug resistance associated protein (MRP) increases resistance to natural product drugs. Cancer Res 54: 357-361, 1994.

21. Kruh GD and Belinsky MG: The MRP family of drug efflux pumps. Oncogene 22: 7537-7552, 2003.

22. Haimeur A, Conseil G, Deeley RG and Cole SP: The MRP-related and BCRP/ABCG2 multidrug resistance proteins: biology, substrate specificity and regulation. Curr Drug Metab 5: 21-53, 2004. 
23. Pituch-Noworolska A,Zaremba $\mathrm{M}$ and Wieczorek A: Expression of proteins associated with therapy resistance in rhabdomyosarcoma and neuroblastoma tumour cells. Pol J Pathol 60 168-173, 2009.

24. Sun JR, Chan MC, Chang TY, Wang WY and Chiueh TS: Overexpression of a transporter gene in a multidrug-resistant human lung cancer cell line. Science 258: 1650-1654, 1992.

25. Izquierdo MA, Scheffer GL, Flens MJ, et al: Broad distribution of the multidrug resistance-related vault lung resistance protein in normal human tissues and tumors. Am J Pathol 148: 877-887, 1996.

26. Steiner E, Holzmann K, Elbling L, Micksche M and Berger W: Cellular functions of vaults and their involvement in multidrug resistance. Curr Drug Targets 7: 923-934, 2006.

27. Tan B, Piwnica-Worms D and Ratner L: Multidrug resistance transporters and modulation. Curr Opin Oncol 12: 450-458, 2000.

28. Scheffer GL, Schroeijers AB, Izquierdo MA, Wiemer EA and Scheper RJ: Lung resistance-related protein/major vault protein and vaults in multidrug-resistant cancer. Curr Opin Oncol 12: $550-556,2000$

29. Giles GI and Sharma RP: Topoisomerase enzymes as therapeutic targets for cancer chemotherapy. Med Chem 1: 383-394, 2005

30. Ruiz-Gómez MJ, Souviron A, Martínez-Morillo M and Gil L: P-glycoprotein, glutathione and glutathione $S$-transferase increase in a colon carcinoma cell line by colchicines. J Physiol Biochem 56: $307-312,2000$

31. Sau A, Pellizzari Tregno F, Valentino F, Federici $G$ and Caccuri AM: Glutathione transferases and development of new principles to overcome drug resistance. Arch Biochem Biophys 500: 116-122, 2010

32. Crist W, Gehan EA, Ragab AH, et al: The third intergroup rhabdomyosarcoma study. J Clin Oncol 13: 610-630, 1995.

33. Tsokos M, Webber BL, Parham DM, et al: Rhabdomyosarcoma A new classification scheme related to prognosis. Arch Pathol Lab Med 116: 847-855, 1992.

34. Reboul-Marty J, Quintana E, Mosseri V, Flamant F, Asselain B, Rodary C and Zucker JM: Prognostic factors of alveolar rhabdomyosarcoma in childhood. An International Society of Pediatric Oncology study. Cancer 68: 493-498, 1991.

35. Chan HS, Thorner PS, Haddad G and Ling V: Immunohistochemical detection of P-glycoprotein-prognostic correlation in soft-tissue sarcoma of the childhood. J Clin Oncol 8: 689-704, 1990.

36. Ambudkar SV, Kimchi-Sarfaty C, Sauna ZE and Gottesman MM: P-glycoprotein: from genomics to mechanism. Oncogene 22 : $7468-7685,2003$

37. Kuttesch JF, Parham DM, Luo X, et al: P-glycoprotein expression at diagnosis may not be a primary mechanism of therapeutic failure in childhood rhabdomyosarcoma. J Clin Oncol 14: 886-900, 1996.

38. Klunder JW, Komdeur R, Van Der Graaf WT, et al: Expression of multidrug resistance-associated proteins in rhabdomyosarcomas before and after chemotherapy: the relationship between lung resistance-related protein (LRP) and differentiation. Hum Pathol 34: 150-155, 2003

39. Molenaar WM, Oosterhuis JW and Kamps WA: Cytologic differentiation in childhood rhabdomyosarcomas following polychemotherapy. Hum Pathol 15: 973-979, 1984.

40. Leuschner I, Harms D, Mattke A, Koscielniak E and Treuner J: Rhabdomyosarcoma of the urinary bladder and vagina: a clinicopathologic study with emphasis on recurrent disease: a report from the Kiel Pediatric Tumor Registry and the German CWS Study. Am J Surg Pathol 25: 856-864, 2001.

41. Molenaar WM, Oosterhuis JW, Oosterhuis AM and Ramaekers FC: Mesenchymal and muscle-specific intermediate filaments (vimentin and desmin) in relation to differentiation in childhood rhabdomyosarcomas. Hum Pathol 16: 838-843, 1985.

42. d'Amore ES, Tollot M, Stracca-Pansa V, Menegon A, Meli S, Carli $M$ and Ninfo V: Therapy associated differentiation in rhabdomyosarcomas. Mod Pathol 7: 69-75, 1994.

43. Prados J, Melguizo C, Fernández A, Aránega AE, Alvarez L and Aránega A: Inverse expression of MDR1 and c-myc genes in a rhabdomyosarcoma cell line resistant to actinomycin D. J Pathol 180: 85-89, 1996.

44. Melguizo C, Prados J, Fernández JE, Vélez C, Alvarez L and Aránega A: Actinomycin $\mathrm{D}$ causes multidrug resistance and differentiation in a human rhabdomyosarcoma cell line. Cell Mol Biol 40: 137-145, 1994
45. Scheper RJ, Broxterman HJ, Scheffer GL, et al: Overexpression of a M(r) 110,000 vesicular protein in non-P-glycoproteinmediated multidrug resistance. Cancer Res 53: 1475-1479, 1993.

46. Izquierdo MA, Shoemaker RH, Flens MJ, Scheffer GL, Wu L, Prather TR and Scheper RJ: Overlapping phenotypes of multidrug resistance among panels of human cancer-cell lines. Int J Cancer 65: 230-237, 1996.

47. Kolfschoten GM, Hulscher TM, Pinedo HM and Boven E: Drug resistance features and S-phase fraction as possible determinants for drug response in a panel of human ovarian cancer xenografts. Br J Cancer 83: 921-927, 2000.

48. Kitazono M, Sumizawa T, Takebayashi Y, et al: Multidrug resistance and the lung resistance-related protein in human colon carcinoma SW-620 cells. J Natl Cancer Inst 91: 1647-1653, 1999.

49. Cocker HA, Hobbs SM, Tiffin N, Pinkerton CR and Kelland LR High levels of the MDM2 oncogene in paediatric rhabdomyosarcoma cell lines may confer multidrug resistance. Br J Cancer 85: 1746-1752, 2001.

50. Taylor AC, Shu L, Danks MK, et al: P53 mutation and MDM2 amplification frequency in pediatric rhabdomyosarcoma tumors and cell lines. Med Pediatr Oncol 35: 96-103, 2000.

51. Peng Y, Chen L, Li C, Lu W, Agrawal S and Chen J: Stabilization of MDM2 oncoprotein by mutant p53. J Biol Chem 276: 6874-6878, 2001.

52. Sola JE, Wojno KJ, Dooley W and Colombani PM: P-glycoprotein status of favorablehistology Wilms' tumor predicts treatment outcome. J Pediatr Surg 29: 1080-1083, 1994.

53. Warmann SW, Heitmann H, Teichmann B, Gratz KF, Ruck P, Hunger $\mathrm{M}$ and Fuchs J: Effects of Pglycoprotein modulation on the chemotherapy of xenotransplanted human hepatoblastoma. J Pediatr Surg 22: 373-386, 2005.

54. Norris MD, Burkhart CA, Marshall GM, Weiss WA and Haber M: Expression of N-myc and MRP genes and their relationship to $\mathrm{N}$-myc gene dosage and tumor formation in a murine neuroblastoma model. Med Pediatr Oncol 35: 585-589, 2000

55. de Cremoux P, Jourdan-Da-Silva N, Couturier J, et al: Role of chemotherapy resistance genes in outcome of neuroblastoma. Pediatr Blood Cancer 48: 311-317, 2007.

56. Asmar L, Gehan EA, Newton WA, et al: Agreement among and within groups of pathologists in the classification of rhabdomyosarcoma and related childhood sarcomas. Report of an international study of four pathology classifications. Cancer 74 : 2579-2588, 1994

57. Newton WA Jr, Soule EH, Hamoudi AB, Reiman HM, Shimada H, Beltangady $\mathrm{M}$ and Maurer $\mathrm{H}$ : Histopathology of childhood sarcomas, Intergroup Rhabdomyosarcoma Studies I and II: clinicopathologic correlation. J Clin Oncol 6: 67-75, 1998.

58. Barr FG: Molecular genetics and pathogenesis of rhabdomyosarcoma. J Pediatr Surg 19: 483-491, 1998.

59. Marchal JA, Prados J, Melguizo C, et al: GR-891: a novel 5-fluorouracil acyclonucleoside prodrug for differentiation therapy in rhabdomyosarcoma cells. Br J Cancer 79: 807-813, 1999.

60. Prados J, Melguizo C, Marchal JA, Vélez C, Alvarez L and Aránega A: Therapeutic differentiation in a human rhabdomyosarcoma cell line selected for resistance to actinomycin D. Int J Cancer 75: 379-383, 1998

61. Leuschner I, Heuer T and Harms D: Induccion of drug resistance in human rhabdomyosarcoma cell lines is associated with increased maturation: possible explanation for differentiation in recurrences? Pediatr Dev Pathol 5: 276-282, 2002.

62. Staibano S, Franco R, Tranfa F, et al: Orbital rhabdomyosarcoma: relationship between DNA ploidy, p53, bcl-2, MDR-1 and Ki67 (MIB1) expression and clinical behavior. Anticancer Res 24: 249-257, 2004.

63. Prados J, Melguizo C, Fernández JE, et al: Induction of drug resistance in embryonal rhabdomyosarcoma treated with conventional chemotherapy is associated with HLA class I increase. Neoplasma 53: 226-231, 2006.

64. Melguizo C, Prados J, Marchal JA, et al: Modulation of HLA class I expression in multidrug-resistant human rhabdomyosarcoma cells. Neoplasma 50: 91-96, 2003. 